\title{
The transition from pediatric to adult services
}

Fernando Coelho das Neves

Serviço de Nefrologia e Transplantação Renal, Centro Hospitalar Lisboa Norte, Portugal

Dear Editor,

It was a very welcome surprise to see another two renal units (Hospital Curry Cabral and Hospital Dona Estefânia, both in Lisbon) initiating pediatric-to-adult nephrology programs. In a letter to the editor, "The transition from pediatric to adult services"1 Vieira et al. presented her initial and promising experience, and we congratulate her on the initiative. We pioneered such an approach back in 1998 with a joint pediatric/adult out-patient clinic where, in the presence of the pediatrician in charge of the case, the Adult-Nephrologist, the patient and a close relative/care giver, all the clinical and social aspects involved were discussed. Particularly the differences between the adult world and the protective environment the youngster used to be in, and how to overcome "aggressive" situations. We published our initial experience in $2007^{2}$ (69 patients) and revisited our data in $2015^{3}$ (151 patients). Unfortunately, neither of these papers nor the Editorial ${ }^{4}$ by Professor J. Stewart Cameron - published together with the 2007 paper - were mentioned by Dr. Vieira in the text or as references.

In order to guarantee compliance with medication and appropriate lifestyle in this age group, a close surveillance is crucial, while still respecting individual autonomy where confidence between the nephrologist and patient plays a crucial role in the process. The sooner we follow a patient, the sooner we gain his/her confidence.

No experience in this subject should be left out since, as with so many other aspects of life, there is a continuum of knowledge in medicine that started many years ago and will continue for many years to come.

Our main obligation, as doctors, is to spread knowledge, not to keep it.

Disclosure of potential conflicts of interest: none declared.

\section{References}

1. Vieira M, Silva C, Abranches M. The transition from pediatric to adult services. Port J Nephrol Hypert 2018; 32(4): 393-394

2. Jorge S, Neves FC, Mendonça E, Stone R, Almeida M, Prata MM. Paediatric nephrology patients moving to adult age: a difficult transition to manage. The experience of a paediatric -to -adult out -patient clinic. Port J Nephrol Hypert 2007; 21(3): 211-221

3. Rodrigues N, Pereira M, Neves F, et al. Growing up with chronic renal disease - The road remains rocky Port J Nephrol Hypert 2015; 29(3): 221-227

4. Cameron JS. The "rocky road" of transition from pediatric to adult care in renal disease. Port J Nephrol Hypert 2007; 21(3): 185-186.

\section{Correspondence to:}

Fernando Coelho das Neves, MD

Serviço de Nefrologia e Transplantação Renal,

Centro Hospitalar Lisboa Norte, Portugal 